Volume 9, No.4, July - August 2020

International Journal of Advanced Trends in Computer Science and Engineering

Available Online at http://www.warse.org/IJATCSE/static/pdf/file/ijatcse372942020.pdf

https://doi.org/10.30534/ijatcse/2020/372942020

\title{
Service Broker Algorithm for Datacenter Selection with light and heavy load in Cloud Computing
}

\author{
Amrita Jyoti ${ }^{1}$, Dr. Rajesh Kumar Pathak ${ }^{2}$, Dr. Pratap Singh ${ }^{3}$ \\ ${ }^{1}$ ABES Engineering College, Ghaziabad, Uttar Pradesh, India, amritajyoti2013@gmail.com \\ ${ }^{2}$ Shri Rawatpura University, India, drrkpathak20@ gmail.com \\ ${ }^{3} \mathrm{Hi}-\mathrm{Tech}$ Group of Institution, Ghaziabad, India,pratapsinghhrgec@gmail.com
}

\begin{abstract}
The cloud brokering architecture is composed of five main players for example, cloud suppliers, cloud merchants, cloud evaluator, cloud transporter and cloud buyers. Every one of the players is the elements that take part in the exchange or procedure in cloud computing. Shoppers make a solicitation on executing the correct undertakings on distributed computing acquired from the cloud supplier. A cloud evaluator gathers the vital data. The capacity of a cloud representative conveys the virtualized framework along with the administration demand depiction and provide for the purchasers. The administration demand depiction comprises of some after standards, for example, improvement, set of the virtual machine, Service Measurement Index (SMI) traits and datacenter. There likewise the chance of having higher preparing time, reaction time and outstanding burden in the chose datacenter additionally underutilization of assets. So as to defeat the previously mentioned issue, it is smarter to choose the datacenters in terms of response time, processing time, workload and cost.
\end{abstract}

Key words: Cloud Amalyist, Cloud Computing, service Broker Policy, Data Center

\section{INTRODUCTION}

These days, the cloud administration has taken a principle key achievement in many entrepreneurs to furnish versatile and adaptable capacity along with figuring abilities in both little and medium-sized organizations. Because of the solid development of the cloud administration, it is hard to adjust the expected clients and choose which choice best addresses their issues. The fundamental job of the cloud administration is, with no outer causes it ought to deal with the installments, customization, information handling, administration and enhancement between the suppliers and administrations [1]. An overall term for the cloud merchant is, it is one of the go-betweens between the clients and cloud suppliers to offer an assistance of joining, customization and total of cloud administrations in CC [2]. As of late, CloudSim and Cloud Analyst is assuming an incredible position in the $\mathrm{CC}$ test system [3]. Datacenter regulator in Cloud Analyst control the server farm exercises, for example, VM creation and pulverization and perform steering between the client's solicitations got from client base through the web.

\section{SIMULATION ENVIRONMENT OF CLOUD BROKER IN VARIOUS CLOUD COMPONENTS}

These days distributed computing offers another vision of facilitating and offering types of assistance in the IT field [12]. In CC, load adjusting, cost demonstrating, virtual machine relocation, vitality the executives and security issues are considered as a significant issue, which doesn't serve the correct assets as a support of the customer [11]. To explore the conduct of enormous scope dispersion framework recreation method is presented in CC. The fundamental advantages of cloud test systems cause a simple to examine over different cloud application. The two commonly used simulation techniques in CC are Cloud Sim and Cloud Analyst [3, 8].

\subsection{Cloud Analyst}

The Cloud Analyst is like Cloud Sim, the main contrast is that new extra highlights are included, additionally named as open source toolbox [8]. In the geologically circulated framework for an enormous scope, every one of the client's outstanding burden has an alternate boundary. To assess it as far as execution and costs Cloud Analyst is presented where the reaction time and information handling time are the two execution assessment measurements, which is based on the head of the Cloud Sim. The fundamental fascinating highlights of Cloud Analyst incorporate the adaptability and simplicity of the Graphical User Interface (GUI).

\section{EFFICIENT SERVICE BROKER ALGORITHM FOR DATACENTER SELECTION}

In CC load adjusting are partitioned into two general classes, for example, datacenter determination likewise named as Data application administration agent and virtual machine the executives named as datacenter regulator. Executing of productive assistance merchant calculation in load adjusting 
can give powerful datacenter determination to up and coming solicitation dependent on their preparing ability. Since a powerful calculation can give minimization of burden on datacenter and decrease accordingly an ideal opportunity for all clients.

In SPBR the server farm is chosen dependent on most reduced system inertness or by least transmission delay. On the off chance that more than one datacenter is closeness an arbitrary determination is given to the approaching solicitation without thinking about the cost, execution, reaction time and another boundary. By this factor, the arbitrarily chose datacenter give bothersome outcomes. For this, in 2017 Nandwani et al. [9] proposed a weight based information determination calculation to improve the exhibition of arbitrary SPBR as far as preparing time, for example, execution and cost.

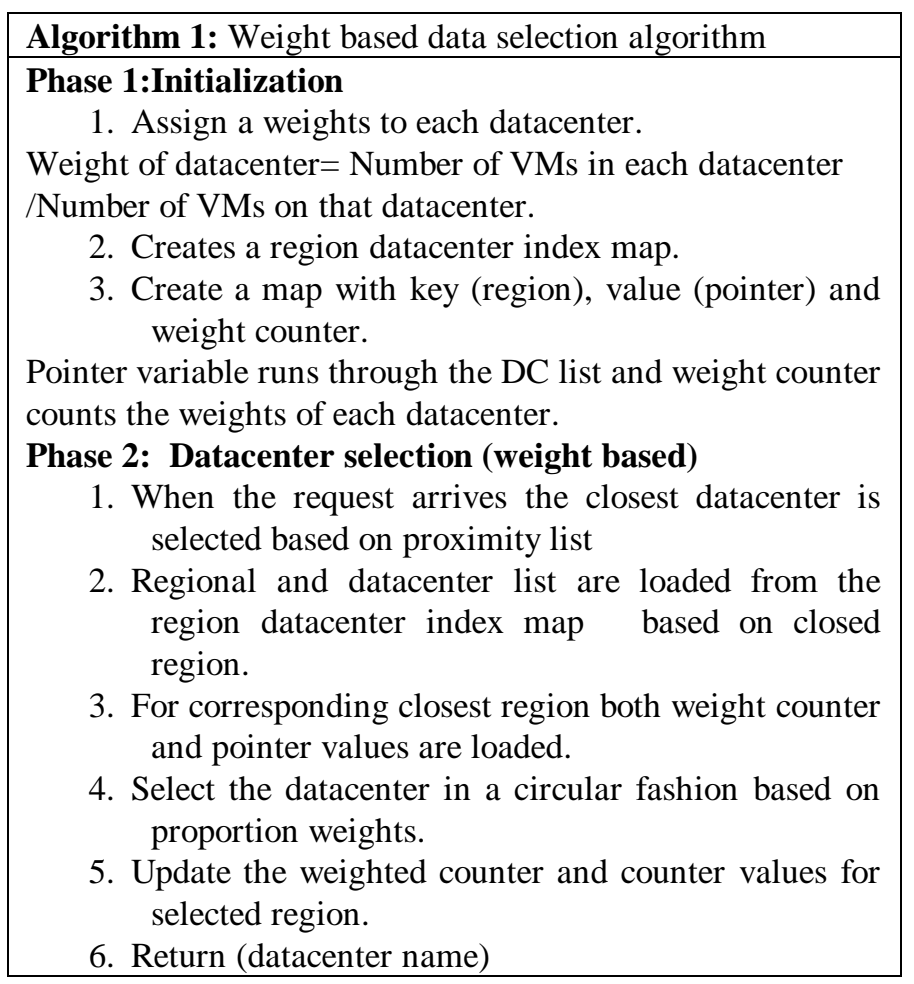

\subsection{Equal Distributer Service Broker (EDSR)}

This algorithm considers the performance and cost of two data centers. When a request is received by the service broker, the algorithm evenly distributes the load among these two data centers. This algorithm search for the Best Performance Datacenter (BPDC) to send the request and uses a virtual machine cost parameter to select the Lowest Cost Datacenter (LCDC). The step for the algorithm is given below:

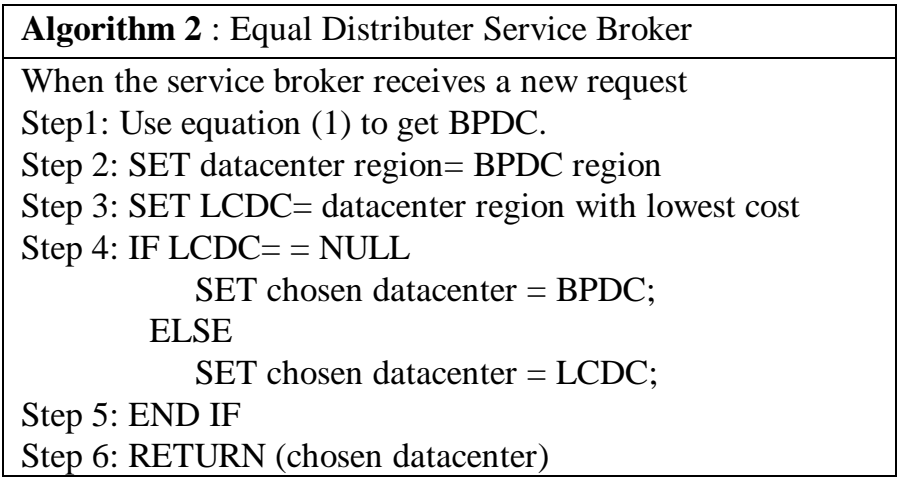

\subsection{Cost- Performance Service Broker Algorithm (C-P SBA)}

This algorithm is the extension of the previous algorithm, it uses two parameters of total latency and the total cost to choose the correct datacenter using a merging technique [9]. The total cost performance calculation is given by,

$C_{\text {total }}=\left(\frac{M I P_{S_{\text {total }}}}{V M_{\text {MIPS }}}\right) \times V M_{\cos t}+U_{D S} \times D T_{\cos t}$

(1)

Where $C_{\text {tota }}$ is represented as total cost, contains both data transfer cost and virtual machine processing cost. $\frac{M I P_{S_{\text {total }}}}{V M_{M I P S}}$ represent the total number of instruction per average processing power assigned to the datacenter. $V M_{\text {cost }}$ indicates the cost of a virtual machine in an hour, $U_{D S}$ represent the data size of the user request and $D T_{\cos }$ is the data transfer cost.

The first part of the equation measures the processing time taken by the virtual machine for a total number of requests and multiplies it with virtual machine cost to find the total cost. The second part of the equation calculates the total data transfer cost by multiplying it with the size of the user's request data. The algorithm is are given in step by step as follows, 


\begin{tabular}{l} 
Algorithm 3 : Cost- performance service broker algorithm \\
\hline When the service broker receives a new request \\
Step1: FOR all datacenter \\
SET total MIPS + = request MIPS \\
Step 2: By using equation (1) calculate the network delay. \\
Step 3: By using equation (2) calculate the total cost for \\
present datacenter. \\
Step 4: IF total cost < minimum cost \\
$\quad$ SET minimum cost = total cost; \\
$\quad$ SET chosen datacenter = current datacenter; \\
Step 5: END IF \\
Step 6: END FOR \\
Step 7: RETURN (chosen datacenter)
\end{tabular}

The above last two algorithms consider cost and performance as a two parameter. The first algorithm equally distributes the load between the lowest cost and best performance datacenter. The second algorithm put two parameters in one equation and choose the best performance with the lowest cost.

\subsection{Testing of Four Algorithm (SPBR, POR, EDSR and C-P SR) in Light and Heavy situation}

The testing of the first situation use 2 datacenters and 5 users and the second situation uses 3 datacenters with 12 users.

\subsubsection{Situation 1: 5 users with 2 datacenters (Light load)}

This first situation is designed for light load testing. The data center configuration (DC) and user base configuration (UC) are provided in Table 1 and 2. Table 1 shows that DC has a different region with different datacenter and virtual machine cost. Table 2 shows that the UC has different data sizes, peak hours and different loads (MIPS) for one-day simulation duration.

\section{Table 1: DC for situation -1}

\begin{tabular}{|c|c|c|c|}
\hline Subject & Region & $\begin{array}{c}\text { Data transfer } \\
\text { cost }\end{array}$ & $\begin{array}{c}\text { Virtual machine } \\
\text { cost }\end{array}$ \\
\hline DC-1 & 0 & 0.2 & 0.2 \\
\hline DC-2 & 5 & 0.1 & 0.1 \\
\hline
\end{tabular}

Table 2: UC for situation -1

\begin{tabular}{|l|l|l|l|}
\hline Subject & MIPS /request & $\begin{array}{l}\text { Peak } \\
\text { hours }\end{array}$ & $\begin{array}{l}\text { Size of data / } \\
\text { hours (bytes) }\end{array}$ \\
\hline UC-1 & 100 & $1-2$ & 200 \\
\hline UC-2 & 500 & $3-5$ & 250 \\
\hline UC-3 & 250 & $5-7$ & 300 \\
\hline UC-4 & 150 & $7-9$ & 100 \\
\hline UC-5 & 300 & $9-11$ & 500 \\
\hline
\end{tabular}

The above table clearly shows that all the user bases are located in region-2, put on 1000 users in peak hours and 100 users in non-peak hours with 60 requests per hour for each user. The table shows each datacenter has a capacity to host 5 virtual machines with memory size $512 \mathrm{MB}$, storage 1000 MB and bandwidth $1000 \mathrm{megabit} / \mathrm{sec}$.

Table 3: Performance analysis in light load situation-1

\begin{tabular}{|l|l|l|l|}
\hline Algorithm & $\begin{array}{l}\text { Maximum } \\
\text { response } \\
\text { time }(\mathrm{ms})\end{array}$ & $\begin{array}{l}\text { Maximum } \\
\text { processing } \\
\text { time }(\mathrm{ms})\end{array}$ & $\begin{array}{l}\text { Overall } \\
\text { cost }(\$)\end{array}$ \\
\hline $\begin{array}{l}\text { Service proximity } \\
\text { based routing }\end{array}$ & 416.98 & 38.52 & 719.46 \\
\hline $\begin{array}{l}\text { Performance } \\
\text { optimized routing }\end{array}$ & 514.38 & 39.96 & 718.11 \\
\hline $\begin{array}{l}\text { Equal distributer } \\
\text { service broker }\end{array}$ & 546.50 & 48.25 & 509.48 \\
\hline $\begin{array}{l}\text { Cost-performance } \\
\text { service broker }\end{array}$ & 512.63 & 39.91 & 718.09 \\
\hline
\end{tabular}

Table 3 shows the comparison results of four algorithms (SPBR, POR, EDSR and CPSR) together with datacenter overall cost, maximum response time and processing time.

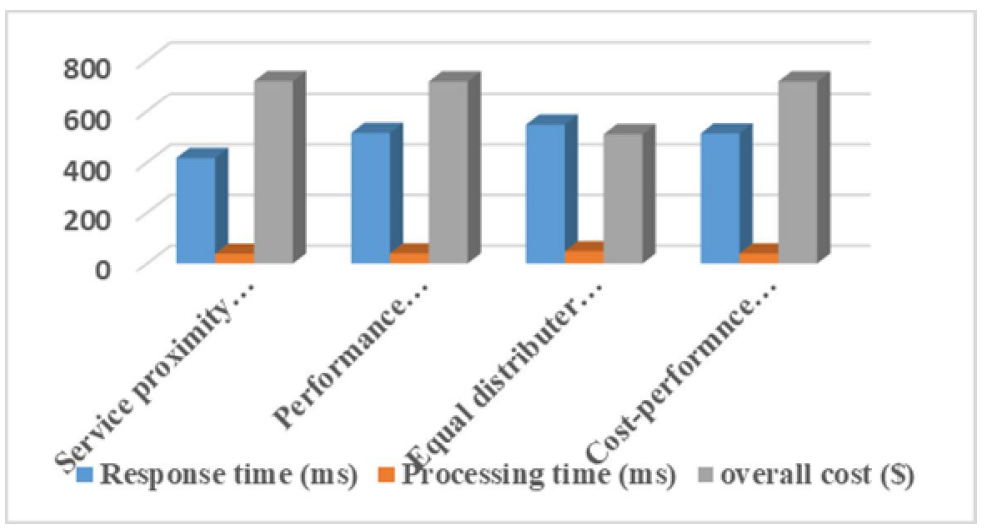

Figure 1: Performance analysis under four service broker algorithm.

The result for Table 3 is shown in Figure 1. It shows that where three algorithms of SPBR, POR, and C-P SR are almost the same. The SPBR algorithm chooses the DC-1 datacenter to send the entire request, while the POR and C-P SR sends only 1 or $2 \%$ of the load to DC-2. Where the EDSR stands between processing time, response time and cost. Using this algorithm, the processing time is reduced by $65 \%$, the response time is reduced by $8 \%$ and the total cost is reduced by $30 \%$. In light load conditions, less algorithm is performed well better and faster than the C-P SR algorithm. 
Amrita Jyoti et al., International Journal of Advanced Trends in Computer Science and Engineering, 9(4), July - August 2020,6747 - 6751

\subsubsection{Situation 2: 12 users with 3 datacenters (Heavy load)}

The second situation is designed for heavy load testing. DC and UC are provided in Table 4 and 5. Table 4 shows that DC has a different region with different datacenter and virtual machine cost. Table 5 shows that the UC has different data sizes, peak hours and different loads (MIPS) for one-day simulation duration.

Table 4: DC for situation -2

\begin{tabular}{|l|l|l|l|}
\hline Subject & Region & $\begin{array}{l}\text { Data transfer } \\
\text { cost }\end{array}$ & $\begin{array}{l}\text { Virtual machine } \\
\text { cost }\end{array}$ \\
\hline DC-1 & 0 & 0.2 & 0.2 \\
\hline DC-2 & 3 & 0.1 & 0.1 \\
\hline DC-3 & 3 & 0.15 & 0.15 \\
\hline
\end{tabular}

Table 5: UC for situation -2

\begin{tabular}{|l|l|l|l|l|}
\hline Subject & Region & $\begin{array}{l}\text { MIPS } \\
\text { /request }\end{array}$ & $\begin{array}{l}\text { Peak } \\
\text { hours }\end{array}$ & $\begin{array}{l}\text { Size of data } \\
\text { (bytes) }\end{array}$ \\
\hline UC-1 & 0 & 500 & $1-3$ & 3000 \\
\hline UC-2 & 2 & 400 & $3-6$ & 5000 \\
\hline UC-3 & 3 & 100 & $6-9$ & 6000 \\
\hline UC-4 & 4 & 200 & $9-12$ & 1000 \\
\hline UC-5 & 5 & 250 & $12-15$ & 2000 \\
\hline UC-6 & 0 & 250 & $15-18$ & 3000 \\
\hline UC-7 & 1 & 100 & $18-21$ & 9000 \\
\hline UC-8 & 2 & 200 & $3-9$ & 4000 \\
\hline UC-9 & 3 & 300 & $21-24$ & 5000 \\
\hline UC-10 & 4 & 250 & $5-7$ & 3000 \\
\hline UC-11 & 5 & 300 & $11-13$ & 2000 \\
\hline UC-12 & 1 & 100 & $21-23$ & 1000 \\
\hline
\end{tabular}

Table 6: Performance analysis in light load situation-2

\begin{tabular}{|l|l|l|l|}
\hline Algorithm & $\begin{array}{l}\text { Maximum } \\
\text { response } \\
\text { time (ms) }\end{array}$ & $\begin{array}{l}\text { Maximum } \\
\text { processing } \\
\text { time (ms) }\end{array}$ & $\begin{array}{l}\text { Overall } \\
\text { cost }(\$)\end{array}$ \\
\hline $\begin{array}{l}\text { Service proximity } \\
\text { based routing }\end{array}$ & 660.82 & 91.45 & 1271.47 \\
\hline $\begin{array}{l}\text { Performance } \\
\text { optimized routing }\end{array}$ & 670.26 & 92.89 & 1268.71 \\
\hline $\begin{array}{l}\text { Equal distributer } \\
\text { service broker }\end{array}$ & 660.26 & 97.68 & 1250.09 \\
\hline $\begin{array}{l}\text { Cost-performance } \\
\text { service broker }\end{array}$ & 660.54 & 83.50 & 1240.08 \\
\hline
\end{tabular}

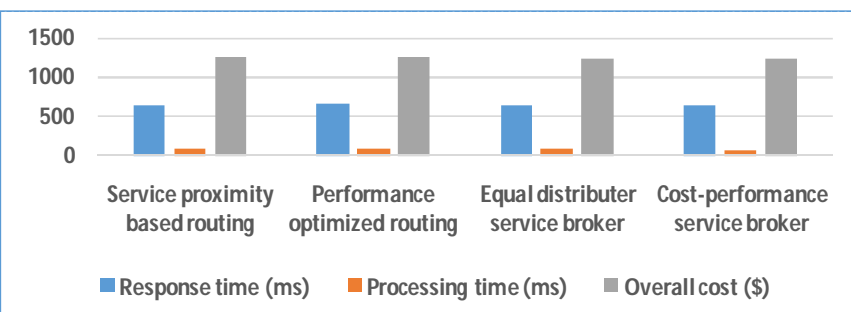

Figure 2: Performance analysis under four service broker algorithm

Table 6 shows the comparison results of four algorithms and the result for Table 6 is provided in figure 2 .

\section{CONCLUSION}

The result of the figure 2 shows that SPBR ignores the cost factor and uses only a performance parameter for performance analysis. EDSR and C-P SR provide a good response time with a $6 \%$ reduction in the total cost and $10 \%$ in processing and response times.This paper presents the general concept of service brokering in cloud computing with some basic techniques that use various service broker policy and a efficient idea about the the datacenter selection. This paper presents the overall idea of administration handling in distributed computing with some fundamental strategies that utilization different help representative strategy and an effective thought regarding the datacenter selection. We additionally exhibit how reenactment procedures, for example, Cloud Analyst are utilized in the cloud model to assess real time issue.

\section{REFERENCES}

1. Z. U. Rehman, F. K. Hussain and O. K. Hussain, "Towards Multi-Criteria Cloud Service Selection”, 2011 Fifth International Conference on Innovative Mobile and 
Amrita Jyoti et al., International Journal of Advanced Trends in Computer Science and Engineering, 9(4), July - August 2020,6747 - 6751

Internet Services in Ubiquitous Computing, DOI 10.1109/IMIS.2011.99, pp. 44-48, 2011.

2. Grivas SG, Kumar TU, Wache H. Cloud broker: Bringing intelligence into the cloud. In2010 IEEE 3rd International Conference on Cloud Computing 2010 Jul 5 (pp. 544-545). IEEE.

https://doi.org/10.1109/CLOUD.2010.48

3. Wickremasinghe B, Calheiros RN, Buyya R. Cloudanalyst: A cloudsim-based visual modeller for analysing cloud computing environments and applications. In2010 24th IEEE international conference on advanced information networking and applications 2010 Apr 20 (pp. 446-452).

4. "Towards Cooperative Cloud Service Brokerage for SLA-driven Selection of Cloud Services", Springer International Publishing Switzerland, R. Silhavy et al. (eds.), Software Engineering in Intelligent Systems, Advances in Intelligent Systems and Computing 349, DOI:10.1007/978-3-319-18473-9_27, pp. 271-281, 2015.

5. E. Badidi, "A Cloud Service Broker for SLA-based SaaS Provisioning", IEEE, pp. 61-66, 2013.Conference on Information Society (i-Society 2013), Toronto, Canada, pp. 61-66 (2013).

6. Amato A, Di Martino B, Venticinque S. Cloud brokering as a service. In 2013 Eighth International Conference on P2P, Parallel, Grid, Cloud and Internet Computing 2013 Oct 28 (pp. 9-16). IEEE. https://doi.org/10.1109/3PGCIC.2013.9

7. Bohn RB, Messina J, Liu F, Tong J, Mao J. NIST cloud computing reference architecture. In 2011 IEEE World Congress on Services 2011 Jul 4 (pp. 594-596). IEEE.

8. Pradeep Singh Rawat, GP Saroha, and Varun Barthwal. Performance evaluation of social networking application with different load balancing policy across virtual machine in a single data center using cloudanalyst. In Parallel Distributed and Grid Computing (PDGC), 2012 2nd IEEE International Conference on, pages 469-473. IEEE, 2012.

9. Nandwani S, Achhra M, Shah R, Tamrakar A, Joshi K, Raksha $S$. Weight-based data center selection algorithm in cloud computing environment. InArtificial Intelligence and Evolutionary Computations in Engineering Systems 2016 (pp. 515-525). Springer, New Delhi.

https://doi.org/10.1007/978-81-322-2656-7_47

10.R. Karim, C. Ding and A. Miri, "An End-To-End QoS Mapping Approach for Cloud Service Selection", IEEE Ninth World Congress on Services, pp. 341-348, 2013.

11. Bholanath Mukhopadhyay, Dr. Rajesh Bose, Dr. Sandip Roy A Novel Approach to Load Balancing and Cloud Computing Security using SSL in IaaS Environment, International Journal of Advanced Trends in Computer Science and Engineering (IJATCSE), vol. 9, no. 2, pp. 2362-2370, march-April 2020. https://doi.org/10.30534/ijatcse/2020/221922020

12. Ariffin, M. A. M., Rahman, K. Ab., Darus, M. Y., Awang, N., Kasiran, Z. Data Leakage Detection in Cloud
Computing Platform, International Journal of Advanced Trends in Computer Science and Engineering (IJATCSE), vol. 8, no. 1, pp. $400-408,2019$.

https://doi.org/10.30534/ijatcse/2019/7081.32019 